\title{
Religião, escrita e sistematização: reflexões em torno dos Annales Maximi
}

\author{
Claudia Beltrão da Rosa[1]
}

\begin{abstract}
Resumo
O tema dos Annales Maximi ocupou - e ainda ocupa - um lugar especial na atenção dos historiadores, e esses livros, a despeito das variantes interpretativas, são geralmente observados à luz da escrita da história e de questões relativas à memória romana. Este artigo aborda o problema dos Annales Maximi sob o viés dos estudos da religião romana, buscando compreender seu lugar no processo de construção e sistematização do conhecimento religioso na urbs entre os séculos III e I a.C.
\end{abstract}

Palavras-chave: Annales Maximi; colégio dos pontífices; religião romana.

\section{Religión, escritura y sistematización: reflexiones sobre los Annales Maximi}

\section{Resumen}

El tema Annales Maximi ocupó y - lo continua ocupando - una posición especial para los historiadores, y esos libros a pesar de sus variaciones de interpretación son generalmente observados por la escritura de la historia y de cuestiones referentes a la memoria romana. Esto artigo aborda el problema de los Annales Maximi al bies de los estudios de la religión romana, con el intuito de comprender su posición en el proceso de construcción y sistematización del conocimiento religioso en urbs, entre los siglos III y I a.C.

Palabras clave: Annales Maximi; colegio de los pontífices; religión romana.

\section{Religion, writing and systematization: reflections on the Annales Maximi}

\begin{abstract}
The topic of the Annales Maximi has been given special attention by historians until today. Apart from varied interpretations, these books are usually considered under the perspective of the writing of history and Roman memory related issues. This paper addresses the problem of Annales Maximi with respect to Roman religion in an attempt to understand its role in the process of constructing religious knowledge and systematization at the $u r b s$ in the $3^{\text {rd }}$ to $2^{\text {nd }}$ centuries BC.
\end{abstract}

Keywords: Annales Maximi; College of Pontiffs; Roman religion.

\section{La religion, l'écriture et la systematization: réflexions sur les Annales Maximi}

\section{Résumé}

Le thème de l'Annales Maximi a eu une attention particulière des historiens jusquà nos jours et, malgré les diverses interprétations, ces ècrits sont généralement considérés du point de vue de lécriture de l'histoire et de la mémoire romaine. Ce texte examine le problème des Annales Maximi par rapport à la religion romaine, dans le but de comprendre son rôle dans le processus de construction et systématisation de la connaissance religieuse à urbs du IIIe-IIe siècles av- JC.

Mots-clés: Annales Maximi; Collège de Pontifes ; Religion Romaine. 
Pontifices [...] quorum auctoritati fidei, prudentiae maiores nostri sacra religionesque et priuatas et publicas commendarunt

(Cícero. Har. resp. 14).

$\mathrm{E}$ m 2009, um colóquio denominado Omnium annalium monumenta: annals, epic and drama in Republican Rome, no Institutum Romanum Finlandiae (IRF), em Roma, trouxe importantes questões ao debate historiográfico sobre a República romana. ${ }^{1}$ Um dos eixos temáticos, denominado Historical documentation before historians: documentary evidence and oral traditions, retomou a discussão sobre as fontes tradicionalmente atribuídas aos historiadores romanos antigos, e os Annales Maximi receberam um grande destaque. Um evento subsequente, denominado Omnium annalium monumenta: historical evidence and historical writing in Republican Rome, em 2013, também em Roma, trouxe novamente o tema dos Annales Maximi à ordem do dia. Mais especificamente, debateram-se questões relativas à natureza, uso e função dos commentarii e das tabulae pontificum e se essas tabulae foram ou não publicadas, na República tardia, sob o título Annales Maximi.

Os Annales Maximi, registros anuais realizados pelo pontifex maximus, ocuparam - e ainda ocupam - um lugar especial na atenção dos historiadores, e esses livros, a despeito das variantes interpretativas e das controvérsias, são geralmente observados à luz da escrita da História e de questões relativas à memória romana. Meu interesse aqui é observar os Annales Maximi sob o viés dos estudos de religião romana. Para tanto, retomarei as referências antigas, passando, então, à observação de seus "atores" principais - o colégio dos pontífices, em geral, e o pontifex maximus, em particular - e das linhas mestras do debate historiográfico sobre esses textos, buscando compreender o papel dos escritos pontificais no processo de construção e sistematização do conhecimento religioso entre os séculos III e I a.C.

\section{Religião, escrita e sistematização}

Na modernidade, um ponto fulcral dos estudos sobre religiões e religiosidades de distintos grupos humanos é perguntar por seus livros sagrados, pelo conjunto de textos que codificariam e armazenariam postulados e conhecimentos religiosos, consolidando formas autorizadas de crenças e rituais e o estabelecimento de hierarquias. Para alguns especialistas atuais - preocupados com a dinâmica dos sistemas religiosos, que implica comunicação de seus conteúdos -, nenhum conceito ou norma pode ser comunicado sem que seja adquirido, codificado, armazenado e transmitido por agentes que busquem preservá-los em suas características. O conhecimento religioso, codificado na linguagem e fixado em versões autorizadas escritas, seria, assim, uma ótima ferramenta na construção de sistemas religiosos de larga escala e expansíveis a outros

'O Colóquio foi organizado por Kaj Sandberg e Christopher Smith e as intervenções, publicadas em 2011, nas Acta Institutum Romanum Finlandiae, em Roma. 
grupos humanos externos ao seu locus original, com variações regionais, decerto, mas sem perder suas características principais. ${ }^{2} \mathrm{O}$ sistema religioso romano, que pode ser percebido, com certa nitidez, nos séculos II e I a.C., expandiu-se em crenças, práticas e formas rituais, atingindo locais e grupos humanos distantes de seu núcleo original na Itália Central, ao longo da constituição do Imperium Romanum, e um dos tópicos centrais da pesquisa sobre a religião romana é a análise das formas dessa expansão e integração religiosa do Imperium. ${ }^{3}$

A historiografia moderna buscou tais livros sagrados na Roma antiga, acreditando que trariam as regras gerais de todos os cultos e que existiriam desde os primórdios de Roma. Os modernos, com base em projeções de crenças atuais no passado, viram também a religião romana como um fenômeno exclusivamente político, criando e divulgando a ideia de que havia uma religião (o "paganismo" $)^{4}$ fria, manipuladora e esvaziada de "conteúdo religioso".5 John Scheid argumenta que "nesse cenário, os escritos sagrados estavam ligados ao nascimento do ritual; eles serviriam para coletar, controlar e petrificar os costumes naturais de comunicação com o divino." ${ }^{\prime 6}$ As discussões dos especialistas sobre a natureza e a organização do conteúdo desses livros foram e ainda são intensas, mas, em geral, pouco se critica a própria noção de "livros sagrados". Scheid, por exemplo, comenta a busca desses livros e as coleções (monumenta) de libri pontificales, augurales etc., feitas no século XIX d.C, a partir de postulados como os declarados por Georg Rohde, um dos mais destacados especialistas modernos nos "livros pontificais", como o que segue:

No início da petrificação do ritual, os livros eram usados para fixar as regras do culto na memória. Isso era feito, primeiro, de um modo muito lacônico, porque todos ainda conheciam o significado do culto. Mas as sociedades se complexificam cada vez mais, e os livros também se tornaram mais complexos. ${ }^{7}$

\footnotetext{
2Harvey Whitehouse; Robert N. McCauley (Eds.), Mind and Religion: Psychological and Cognitive Foundations of Religiosity, Walnut Creek, Altamira Press, 2005; Harvey Whitehouse; Luther H. Martin (Eds.), Theorizing Religious Past: Archaeology, History, and Cognition, Walnut Creek, Altamira Press, 2004.

3Há uma extensa bibliografia sobre o tema. Destaco aqui as obras de Clifford Ando, "Diana in the Aventine", In: Hubert Cancik; Jörg Rüpke, Die Religion des Imperium Romanum, Tübingen, Mohr Siebeck, 2009, p. 99-113, e The matter of the Gods: Religion and the Roman Empire, Berkeley, University of California Press, 2008; de Andreas Bendlin, "Peripheral centres - central peripheries: religious communications in the Roman Empire", In: Hubert Cancik; Jörg Rüpke, Römische Reichsreligion and Provinzial religion, Tübingen, Mohr Siebeck, 1997, p. 35-65; de Greg Woolf, "World Religion and World Empire in the Ancient Mediterranean", In: Hubert Cancik; Jörg Rüpke, Die Religion des Imperium Romanum, Tübingen, Mohr Siebeck, 2009, p. 19-35, e de Simon Price, "Religious Mobility in the Roman Empire", Journal of Roman Studies, The Society for the Promotion of Roman Studies, vol. 102, 2012, p. 1-19.

4"Paganismo" é um termo cunhado pela invectiva cristã que teve muito sucesso no século XIX. É um termo de nítido teor pejorativo, invariavelmente apresentado sob a forma do modelo cristianismo versus paganismo, no qual o primeiro termo é euforizado, e o segundo, disforizado, e que leva à ideia equivocada de que haveria uma unidade religiosa na antiguidade romana, o que revela não apenas visões projetivas de crenças atuais no passado, como também a permanência de uma visão cristã da história que marcou indelevelmente o modo de se ver e interpretar o passado.

${ }^{5}$ Ver detalhamento do tema em Claudia Beltrão da Rosa, "A Religião na urbs", In: Gilvan Ventura da Silva; Norma Musco Mendes (Orgs.), Repensando o Império Romano, Rio de Janeiro, EdUFES; Mauad X, 2006, p. 137-159.

${ }^{6} J o h n$ Scheid, "Oral tradition and written tradition in the formation of sacred law in Rome", In: Clifford Ando; Jörg Rüpke (Eds.), Religion and Law in Classical and Christian Rome, Stuttgart, PawB 16, 2006, p. 16.

${ }^{7}$ Georg Rohde apud Idem, Ibidem, p. 17.
} 
Na religião romana, contudo, se textos escritos eram importantes, constituíam apenas um dentre outros elementos que instrumentalizavam as práticas religiosas. A tradição religiosa romana, rigorosamente falando, jamais foi fixada em algum suporte literário que pudesse ser considerado um conjunto de "escrituras" do tipo cristão, do qual emanassem doutrinas ou diretivas teológicas para a prática religiosa.

É certo que a escrita já existia em Roma muito antes do século IV a.C., e inscrições indicam que a linguagem escrita era usada no Lácio desde, pelo menos, o século VIII a.C., principalmente para marcar a posse de terras e de objetos e registrar regulamentos religiosos e legais; porém, uma cultura literária propriamente dita não é anterior ao período tradicionalmente denominado "República média". Atualmente, é consenso que, a partir do século III a.C., textos escritos tornaram-se parte do "arsenal" religioso romano, compilando-se hinos, orações, regras rituais, prescrições, oráculos etc., mas, rigorosamente falando, é um equívoco atribuir-lhes uma centralidade na vida religiosa como a reconhecida para as religiões monoteístas mundiais modernas. ${ }^{8}$

O processo pelo qual uma cultura literária religiosa teve início em Roma se insere no movimento geral que levou ao incremento da escrita como um dos veículos pelos quais a comunicação pública, especialmente entre os membros da elite romana, se deu. A escrita da tradição - e o controle da mesma tornou-se paulatinamente, a partir do século III a.C., fonte de autoridade e de disputa para os aristocratas, criando e recriando tradições (incluindo o mos maiorum). ${ }^{9}$ Para Thomas Habinek, as audiências das performances literárias não eram restritas aos círculos aristocráticos, ampliando-se e atingindo um corpo social mais amplo, por exemplo, por meio das procissões e inscrições funerárias, das construções públicas e das obras visuais etc., ultrapassando, mas não excluindo, o contexto das sodalitates de banquetes. ${ }^{10}$ A literatura do período tanto criou tradições como se inseriu nessa mesma tradição que estava sendo criada. Habinek analisa o processo de institucionalização da literatura como um empreendimento escrito, profissional e masculino, considerando os meios pelos quais tal literatura se constituiu como uma atividade masculina e aristocrática, que situa convenientemente todo o corpo social, incluindo as mulheres, de acordo com ela, e diz:

\footnotetext{
${ }^{8}$ A maior parte desses escritos, emanados de diversos collegia sacerdotais e veiculados em diversos suportes materiais, não chegou até nós, e a muitos deles temos acesso apenas mediante pequenos fragmentos epigráficos e referências no extenso e variado conjunto da literatura latina.

${ }^{9} \mathrm{O}$ mos maiorum, considerado um sistema arcaico de valores morais e práticos da aristocracia romana e ao qual escritores como Cícero se remetem frequentemente como argumento de autoridade, é, de fato, uma criação da literatura médio e tardo-republicana. E, segundo Habinek, "O mos maiorum era algo que você conhece, mas também algo que você faz. E uma das coisas que você faz ao observar o mos maiorum é participar das exortações, julgamentos e autocrítica ritualizadas que têm como propósito o reforço de sua própria aderência ao mos maiorum". Thomas Habinek, The Politics of Latin Literature: Writing, Identity and Empire in Ancient Rome, Princeton, Princeton University Press, 1998, p. 54.

${ }^{10}$ Thomas Habinek, The Politics of Latin Literature: Writing, Identity and Empire in Ancient Rome. Princeton, Princeton University Press, 1998, p. 54. Ver também Nevio Zorzetti, “The carmina convivalia”, In: Oswin Murray (Ed.), Sympotica: A Symposion on the Symposion. Records of the $1^{\text {st }}$ Symposion on the Greek Symposion, Oxford, Clarendon Press, 1990.
} 
A transformação das práticas culturais que ocorreram durante e imediatamente após a Segunda Guerra Púnica deve ser vista não como a invenção da literatura per se, mas como uma revolução na sociologia da produção literária. Três desenvolvimentos definem esta revolução: a ênfase na escrita, a profissionalização da performance e a importação de profissionais. Enquanto a cultura literária arcaica parece ter sido caracterizada por performances que não eram necessariamente transmitidas por escrito, a nova cultura de fins do século terceiro e início do século II a.C. estava intimamente conectada pela preservação, pela importação e pela circulação de textos. ${ }^{11}$

A mudança histórica é difícil de analisar, envolvendo muitas áreas e aspectos da vida e, nela, vários fatores interagem. Para além do surgimento de um espaço público na cidade de Roma (visível para nós), das práticas de comunicação nesse espaço e da religio publica, trata-se de um grande processo de mudança social e cultural. Numa cidade que se ampliava em todos os sentidos, a comunicação entre os diferentes grupos e os laços entre eles impulsionavam o desenvolvimento das instituições em geral e das formas religiosas em particular. Assiste-se a um processo de sistematização e de organização pública na "República média", na constituição e articulação de normas que regulavam as atividades públicas e o desenvolvimento de instituições capazes de garantir e de controlar a continuidade da atividade religiosa, incluindo as várias inovações de práticas e as criações institucionais do período. As inovações mais destacadas são, provavelmente, os sacerdócios públicos e a organização desses sacerdócios em collegia. Alguns dos principais collegia da "República tardia" já são detectáveis na passagem dos séculos IV-III a.C., e talvez um elemento importante desse movimento tenha sido o desenvolvimento da cultura literária e do uso institucionalizado da escrita. No caso da religio publica, os registros sacerdotais, as performances dramáticas, o épico e a historiografia contribuíram para sistematizar o conhecimento religioso, mas tal desenvolvimento foi, muitas vezes, plural e aparentemente incoerente, demandando estudos pontuais e de conjunto.

Em suma, práticas e instituições que tradicionalmente atribuímos a um genérico "período republicano" surgem e são criadas entre fins do século IV e o século II a.C., como colégios sacerdotais, magistraturas, rituais religiosos, o cursus honorum, dentre outras. Assim, aquilo que geralmente surge na historiografia moderna como sendo tradicional ou ancestral nos séculos II e I a.C. podia ser uma criação relativamente recente. ${ }^{12}$ Do mesmo modo, aquilo que se acreditava entrever na chamada "República média" como um quadro de práticas religiosas tradicionais pode ser verdadeiro para alguns rituais e crenças da religio domestica e de cultos gentilícios, mas é possível que, no

\footnotetext{
"Thomas Habinek, The Politics of Latin Literature: Writing, Identity and Empire in Ancient Rome, Princeton, Princeton University Press, 1998, p. 37.

${ }^{2}$ Ver especialmente Jörg Rüpke, Religion in Republican Rome: Rationalization and Ritual Change, Philadelphia, University of Pennsylvania Press, 2012.
} 
que tange à religio publica, fosse muito mais recente do que se supunha até pouco tempo atrás, pois,

A religião romana, como a conhecemos, é em grande parte o produto da República média e tardia, do período compreendido entre a vitória de Roma sobre seus aliados latinos em 338 a.C. e a tentativa dos povos itálicos, na Guerra Social, de estancar a dominação romana, resultando na vitória de Roma sobre toda a Itália em 89 a.C. Impelida pelas próprias mudanças na estrutura e na natureza da aristocracia romana, a religião romana consolidou, canalizou e delimitou tais mudanças..$^{13}$

A ritualização das ações coletivas, ao dar-lhes uma forma estável num espaço determinado, operava como um poderoso meio de controle social vertical e horizontal, criando o que denominamos religio romana, um produto de muitos e longos processos sociais e institucionais, realizados por indivíduos e grupos em circunstâncias particulares e, a partir do século III a.C., textos escritos se uniram a outras formas de comunicação religiosa, política e institucional e se tornaram "meios" para o exercício do poder.

Restringindo-me ao âmbito jurídico e político, a escrita era utilizada para fixar textos de leis e decisões há muito na urbs, mas protocolos de reuniões ou relatos de ações parecem só ter se tornado regulares por volta de meados do século III a.C., especialmente com os arquivos pontificais e os registros de encontros "diplomáticos" com representantes de povos estrangeiros, pois a forma principal de comunicação era oral. À época de Catão, contudo, a escrita passou a desempenhar um importante papel na luta interna pelo poder e, a partir de fins do século III a.C., parece ter havido o interesse em sistematizar o conhecimento religioso, ressaltando-se a importância da palavra escrita para as atividades rituais e para o controle pontifical do calendário na República. ${ }^{14}$

No início do século II a.C., a escrita era usada por sacerdotes, magistrados e senadores (tratados, leis, censo, protocolos etc.) e estava consolidada no espaço público. Os textos sacerdotais, como os demais, eram símbolos de poder e de autoridade ${ }^{15} \mathrm{e}$, dentre esses textos, os "livros pontificais" receberam uma grande atenção da historiografia moderna que, como pontuamos, tendeu a ver a religião romana como um conjunto de rituais desprovidos de "sentido religioso", como apenas um instrumento político para entronizar regras e proibições. ${ }^{16}$

\footnotetext{
${ }^{13}$ Jörg Rüpke, Religion in Republican Rome: Rationalization and Ritual Change, Philadelphia, University of Pennsylvania Press, 2012, p. 1.

${ }^{14} / d e m$, The Roman Calendar from Numa to Constantine: Time, History, and the Fasti, Chichester, Malden-MA, Wiley-Blackwell, 2011 (1a ed. alemã, 1995).

${ }^{15} \mathrm{Cf}$. Mary Beard, "Writing and Religion", In: Sarah I. Johnston (Ed.), Ancient Religions, Cambridge-Mass, Harvard University Press, 2007, p. 127-138; Tim Cornell, "The tyranny of the evidence: a discussion of the possible uses of literacy in Etruria and Latium in the archaic age", In: Mary Beard et al., "Literacy in the Roman World," Journal of Roman Archaeology, Suppl. 3, 1991, p. 7-34.

${ }^{16} \mathrm{Cf}$. Claudia Beltrão da Rosa, "A Religião na urbs", In: Gilvan Ventura da Silva; Norma Musco Mendes (Orgs.), Repensando o Império Romano, Rio de Janeiro, EdUFES; Mauad X, 2006, p. 137-159; ver também: C. Robert Philipps III, "Approaching Roman Religion: the case for Wissenschaftsgeschichte", In: Jörg Rüpke, $A$ Companion to Roman Religion, Blackwell Companions to the Ancient World, Oxford, Blackwell Publishing Ltd., 2007, p. 10-28.
} 
A pesquisa recente, contudo, busca ultrapassar essa visão anacrônica e cristianizante, e a renovação dos estudos sobre as religiões antigas vem trazendo boas contribuições para uma revisão dos postulados tradicionais sobre a vida religiosa romana, aprofundando nossa compreensão sobre o passado romano.

Com tal base, apresentarei algumas observações sobre o colégio dos pontífices e o presumido autor dos Annales Maximi, o pontifex maximus, e, a seguir, alguns estudos modernos que são referências sobre o tema, buscando fornecer elementos para a compreensão dos debates que cercam esses "livros" no que tange aos estudos sobre a religião romana.

\section{O colégio dos pontífices}

O colégio dos pontífices se destaca no interesse historiográfico moderno, cuja ênfase na documentação textual (ainda) é notória. Não há, contudo, nenhum registro direto do colégio pontifical; não nos chegou nenhum fragmento de seus arquivos. Referências literárias indiretas e cópias de inscrições contendo trechos de decretos pontificais são o que há. A documentação literária, contudo, fornece muitas informações sobre o colégio dos pontífices, e tais dados têm sido submetidos a críticas e cotejamentos com outros tipos documentais, resultando numa retomada do interesse dos estudiosos por esse colégio sacerdotal romano. Novas questões vêm sendo levantadas nos últimos anos, a partir de preocupações distintas das que fundamentaram as abordagens sobre a religião romana em geral e sobre os pontífices em particular, de fins do século XIX até cerca da década de 1980.

\section{Os pontífices, regra geral, eram especialistas em ius sacrum: a investigação de prodigios, promessas, adoção e heranças, organização e gestão do tempo}

Alguns desses textos antigos constituem-se como exposições do que o colégio dos pontífices "deveria ser" ou representações ideais do mesmo. De Varrão, em suas Antiquitates rerum diuinarum, dedicadas ao pontifex maximus Júlio César e que nos chegou em fragmentos, temos apenas duas passagens com referências explícitas ao colégio (Ant. diu, 51, 52), mas depreende-se, a partir do sumário de Agostinho (Ciu. Dei. VI, 3), a centralidade do mesmo na obra. Cícero, no De re publica, 2, apresenta os pontífices à frente das caerimonia, acrescentando-lhes os flâmines, os sálios e as vestais e atribuindo ao colégio a decisão sobre os sacra, definidos como "práticas religiosas", sem especificar se seria a realização propriamente dita dessas cerimônias ou sua supervisão. No De haruspices responso, 14, Cícero comenta as funções pontificais de modo semelhante e, às funções relativas aos sacra, acrescenta competências públicas 
e privadas, mencionando ações que podiam ser realizadas por outras pessoas magistrados, por exemplo - , sobre as quais, contudo, os pontífices detinham algum tipo de controle. E acrescenta, no $\$ 18$, uma observação relevante para nós: os pontífices teriam competência geral em rituais solenes. $\mathrm{O}$ adjetivo sollemnis significa aqui: "que se repetem anualmente", talvez indicando que aquilo que estava sob a competência do colégio eram as cerimônias regulares $^{17}$ e destacando seu controle do tempo social, expresso no calendário. No $D e$ natura deorum, I, 122, Cícero novamente sugere os sacra como competência dos pontífices e apresenta a religião romana dividida entre sacra e auspicia, competência dos áugures, acrescentando um terceiro termo, as predições dos sacerdotes da Sibila - os quimdecemuiri sacris faciundis. ${ }^{18} \mathrm{E}$, no De legibus, vemos uma apresentação mais detalhada (e idealizada?) das funções dos pontífices, derivada de seus ideais filosóficos e políticos. ${ }^{19}$ Nas leges de religione, Cícero aborda a organização dos sacerdotes e suas funções, além de dissertar sobre a fixação do calendário, ou seja, o ciclo anual das festas (Leg. II, 19-20).

Tito Lívio também destaca os pontífices entre os sacerdócios públicos romanos, afirmando que Numa estabelecera o colégio "para que nenhuma parte do direito divino fosse perturbada ao se negligenciar os ritos dos ancestrais ou ao adotar ritos estrangeiros" (Ab urbe condita, I, 20, 5-7) ${ }^{20}$ E, nas Res Gestae de Augusto, o pontificado, o augurato e o quindecenvirato são mencionados como os três primeiros entre os quatro maiores colégios sacerdotais do principado $(R G, 7.3)$, seguidos pelos septemuiri epulones. ${ }^{21}$

Pontífices e áugures, portanto, surgem nos textos antigos dividindo competências relativas aos dois principais campos da religião romana, os auspicia - criados por Rômulo, segundo a tradição (e.g. Cícero, Rep. 2) - e os sacra - atribuídos a Numa (e.g. Cícero. ND, III, 5). Observe-se que o primeiro campo se relaciona com os sinais enviados por Júpiter (no sentido de seres divinos/seres humanos), e o segundo, em sentido inverso, com os sinais enviados pelos seres humanos às divindades. Depreendemos da documentação competências pontificais em assuntos relativos aos sacra, desde as determinações de data, lugar e vítima nas cerimônias públicas, até as competências como experts de saberes relativos aos sacra. ${ }^{22}$ Tito Lívio acrescenta que os sacra públicos e privados eram regidos por decretos dos pontífices

\footnotetext{
${ }^{17}$ Ego uero primum habeo auctores ac magistros religionum calendarum maiores nostros [...] qui statas sollemnisque caerimonias pontificatu, rerum bene gerendarum auctoritates augurio, fatorum ueteris praedictiones Apollinis uatum libris, portentorum expiationes Etruscorum disciplina contineri putauerunt (Har. Resp. 18).

${ }^{18}$ Os quindecimuiri sacris faciundis eram os sacerdotes responsáveis pelos Livros Sibilinos, bem como por emitir pareceres em processos de introdução de novos cultos e divindades em Roma.

${ }^{19}$ Cf. Claudia Beltrão da Rosa, "O uir bonus e a prudentia ciuilis em Marco Túlio Cícero", In: Sônia R. Rebel de Araújo; Claudia Beltrão; Fábio Duarte Joly, Intelectuais, Poder e Política na Roma Antiga, Rio de Janeiro, NAU, 2010, p. 21- 62.

${ }^{20}[$ Numa] Cetera quoque omnia publica priuataque sacra pontificis scitis subiecti [...] ne quid diuini iuris neglegendo patrios ritus peregrinosque adsciscendo turbaretur (I, 20, 5-7).

${ }^{21}$ Colégio composto, após Sila, por sete sacerdotes responsáveis pela supervisão dos jogos (Ludi) regulares em Roma.

${ }^{22}$ Mary Beard, "Priesthood in the Roman Republic", In: Mary Beard; John North (Ed.), Pagan Priests: Religion and Power in the Ancient World, London, Duckworth, 1990, p. 17-48, 36-37.
} 
e atribui ao colégio decisões com poderes de natureza jurídica. Dentre tais competências, vemos as funções de conselheiros e intérpretes, a supervisão de atores religiosos (magistrados e outros sacerdotes), a investigação de prodígios (procuratio prodigiorum), a regulamentação dos $u o t a^{23}$ e a declaração de serem sacerdotes de "todos os deuses" (A.u.c. 1, 20).

Segundo tal documentação, as decisões pontificais eram expressas por fórmulas que faziam referência aos pontífices em conjunto, ao seu caráter colegiado. Suas decisões e conselhos eram transmitidos pelo pontifex maximus ou por seu representante. E, segundo Tito Lívio, até 206 a.C. o pontifex maximus não podia sair da Itália, considerando-se que a ela estava ligado pela cura sacrorum (A. u. c. 28.38,12; 28.44, 11), e esse costume teria sido abandonado somente em 131 a.C. (Perioch. 59). ${ }^{24}$ Há várias menções em inscrições de decretos ou permissões pontificais em matéria de direito funerário, revelando que o colégio também respondia a demandas formuladas por indivíduos privados, apesar de algumas inscrições indicarem que assuntos considerados de menor importância eram delegados aos kalatores (e.g. CIL VI, 712, 2186, 31034).

Devido às suas atividades tanto como experts religiosos quanto como atores do culto, ao lado de outros membros de seu colégio, os pontífices surgem com destaque à frente dos sacra, como o definiu Cícero. Em suas apresentações teóricas do pontificado e em seus relatos sobre as origens desse sacerdócio, os antigos punham o acento na atividade jurídica exercida por esses sacerdotes em matéria religiosa, face às diversas categorias de interlocutores. Para Françoise van Haeperen, as competências pontificais são voltadas, em geral, para a manutenção e a restauração da pax deorum:

[...] por seu papel de experts e de conselheiros, os pontífices ofereciam aos magistrados, ao Senado e aos particulares os meios de restabelecer as boas relações com os deuses quando estas eram rompidas, ou de se precaver em situações nas quais essas relações eram arriscadas. ${ }^{25}$

O pontifex maximus surge em nossas fontes como o representante de seu collegium; falava em seu nome, é possível que convocasse seus colegas e presidisse as reuniões e era ele quem "escolhia" as vestais, os flâmines e o rex sacrorum. ${ }^{26}$ Contudo, as decisões pontificais são apresentadas como decretos do colégio que, para serem válidas, precisavam garantir a presença de pelo menos três sacerdotes, mas a ausência do pontifex maximus não impedia o

\footnotetext{
${ }^{23}$ Promessas solenes; trata-se, aqui, das promessas feitas por magistrados quando da elevação ao ofício. ${ }^{24} U$ ma nova função religiosa no colégio dos pontífices, o promagister, surgiu durante o principado, atestada por uma inscrição de 155 d.C. (CIL, VI 212O, ILS 8380, CIL, VI, 32398a) e, anteriormente, para o colégio dos Arvais, que substituía o pontifex maximus na Itália em caso de afastamento. Cf. John Scheid, "Romulus et ses frères. Le College des Frères Arvales. Modèle de culte public dans la Rome des Empereurs". BEFAR 275, Paris, De Boccard, 1990, p. 220-228, 242

${ }^{25}$ Françoise van Haeperen, Le Collège Pontifical (3ème s.a.C.-4ème s.p.C.): Contribuition à l'étude de la religion publique romaine, Bruxelles-Rome, Institut Historique Belge de Rome, Brepols Publishers, 2002, p. 429.

${ }^{26}$ Ver quadro da composição dos principais colégios sacerdotais romanos em Claudia Beltrão da Rosa, "A Religião na urbs", In: Gilvan Ventura da Silva; Norma Musco Mendes (Orgs.), Repensando o Império Romano, Rio de Janeiro, EdUFES; Mauad X, 2006, p. 143.
} 
colégio de tomar decisões, constituindo o princípio romano do tres faciunt collegia (cf. Cícero, De domo sua, 2-3). Provavelmente, o pontifex maximus tinha uma posição eminente em seu colégio e talvez o representasse, diferentemente dos demais collegia, até mesmo do colégio dos áugures, cujo augure maximus não parece ter a mesma função representativa.

Em suma, o colégio pontifical tinha uma estrutura complexa, englobando pontífices e outros sacerdócios. Como outros collegia sacerdotais, é possível que os pontífices agissem entre as reuniões formais e os banquetes privados aristocráticos, tendo nesses banquetes uma importante forma de comunicação. Os pontífices, regra geral, eram especialistas em ius sacrum: a investigação de prodígios, promessas, adoção e heranças, organização e gestão do tempo. ${ }^{27}$ O Senado, os magistrados, outros sacerdócios, o populus em seus comitia e, mesmo, priuati, podiam solicitar o auxílio dos sacerdotes especialistas nos sacra, e os pontífices surgem como conselheiros em nossas fontes, designadamente em questões relativas à pax deorum/ira deorum, como a procuratio prodigiorum, a instauratio de cerimônias, questões de propriedades (divinas, humanas, dos Manes), promessas, profanações de lugares sagrados, dedicações, heranças, adoções, e sobre a realização dos ludi Romani e dos ludi Plebeii. ${ }^{28}$

Voltemos agora a atenção aos registros sacerdotais. Mary Beard, John North e Simon Price comentam os registros sacerdotais como uma parte significativa das funções tradicionais dos sacerdotes. Sobre os pontífices, argumentam:

Há uma estreita conexão [...] entre seu interesse na continuidade da família e em sua prática de manter registros; e muitas de suas funções compartilham um interesse para com a preservação, do passado ao futuro, de status e direitos nas famílias, entre as gentes e na comunidade com um todo - e também com a transmissão ao futuro de ritos ancestrais. Isso garante ao calendário também um papel central, com sua organização do tempo anual e em suas funções correspondentes, e sua ênfase na prática ritual transmitida como um modelo para o futuro. Os pontífices [...] ligam o passado ao futuro pela lei, pela memória e pelo registro. ${ }^{29}$

\footnotetext{
${ }^{27}$ Ressaltamos a participação dos membros do colégio dos pontífices nas festas religiosas tradicionais o colégio tem uma importância quase exclusiva nas festas relacionadas ao ciclo natural do ano, exceção feita à festa de Dea Dia, realizada pelos Arvais, sobre a qual temos documentos relativos a consultas dos Arvais ao colégio dos pontífices acerca da execução do rito, e as Fornacalia, de fevereiro, celebradas pelos membros das cúrias, que faziam a torrefação dos grãos. Já nas festas do ciclo cívico, vemos maior variedade de celebrantes (outros collegia, magistrados). Há festivais para os quais não temos informação sobre os celebrantes (Terminalia, Equirria), mas os pontífices celebravam um bom número delas (Agonalia, Carmentalia, Virgo parentat, Quirinalia, Regifugium, Argeus, Vestalia, uitutatio, Equus October, Bona Dea, Larentalia, além dos sacrifícios das Kalendas, das Nonas e dos Idos). É possível que os pontífices participassem com os magistrados dos sacrifícios aos Penates do Lavinium, e atesta-se também a participação dos pontífices em cerimônias circunstanciais, como a confarreatio (a forma antiga do conuentio in manum), diffarreatio, a assistência a magistrados (por exemplo, quando dos votos extraordinários, seguidos de um senatus consultum, o magistrado era assistido pelo pontifex maximus, que lhe ditava a fórmula: praeiunte pontifice maximo).

${ }^{28}$ Françoise van Haeperen, Le Collège Pontifical (3ème s.a.C.-4ème s.p.C.): Contribuition à létude de la religion publique romaine, Bruxelles-Rome, Institut Historique Belge de Rome, Brepols Publishers, 2002, p. 215-413.

${ }^{29}$ Mary Beard; John North; Simon Price, Religions of Rome, Vol. 1, Cambridge, Cambridge University Press, 1998, p. 26.
} 
A historiografia moderna buscou recompor tais registros, sem grande sucesso, e, dentre eles, os Annales Maximi se destacavam como tendo sido os mais importantes, supostamente por terem sido emanados do pontifex maximus, apesar de não haver nenhuma evidência direta de sua existência, apenas citações e referências tardias. Importa, portanto, observar as linhas gerais do debate moderno sobre esses textos.

\section{O problema (moderno) dos Annales Maximi}

Os Annales Maximi foram mencionados por autores antigos, e as referências mais extensas a esses livros são de Catão (Orig. 4 = Gell. NA 2.28.6), Cícero (De Or. 2.12.51), Tito Lívio (6.1.2; 9.46.5), Sérvio (Aen. 1.373), Macróbio (Sat. 3.2.17) e Aulo Gélio ( $N A$ 4.5.6).$^{30}$ Essas passagens geraram muitas controvérsias e grandes discussões na modernidade. Segundo Cícero, por exemplo, o pontifex maximus compilava o registro dos eventos mais significativos do ano e o arquivava na Regia, sua residência oficial, registrando eventos políticos, religiosos e naturais; para Sérvio, os Annales Maximi estavam compilados em 80 livros.

Os Annales Maximi ainda levantam muitas dúvidas e problemas, incluindo debates sobre a própria existência desses livros, sobre como teriam sido compilados, quando e com base em quê, de quem seria a autoria, entre outros. Se de fato existiram, o que estava incluído nesses registros, segundo os autores antigos? A mais antiga menção literária aos registros pontificais é, possivelmente, um fragmento de Catão (fr. 77 Peter = A. Gell. NA 2.28.6), que compara sua própria obra à tabula do pontifex maximus, declarando que eclipses e os preços de cereais não seriam assuntos para sua história, e tal declaração seria uma pista de que talvez esses fossem temas dos Annales Maximi. Sobre o conteúdo da tabula, esta é a mais antiga referência presumida. Os conteúdos e o método de arquivamento e conservação dessas tabulae também não são claros; não há referências e abundam as especulações modernas. A comparar

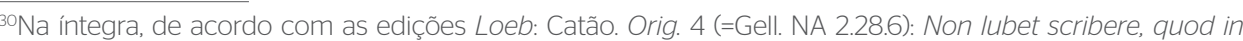
tabula apud pontificem maximum est, quotiens annona cara, quotiens lunae aut solis lumine caligo aut quid obstiterit; Cícero. De Or. 2.12.51: Erat enim historia nihil aliud nisi annalium confectio, cuius rei memoriaeque publicae retinendae causa ab initio rerum Romanorum usque ad P. Mucium pontificem maximum res omnes singulorum annorum mandabat litteris pontifex maximus referebatque in album et proponebat tabulam domi, potestas ut esset populo cognoscendi; ei qui nunc annales maximi nominantur; Tito Lívio, 6.1.2: [...] res cum uetustate nimia obscuras, uelut quae magno ex interuallo loci uix cernuntur, tum quod paruae et rarae per eadem tempora litterae fuere, una custodia fidelis memoriae rerum gestarum, et quod, etiam si quae in commentariis pontificum aliisque publicis priuatisque erant monumentis, incensa urbe pleraeque interiere; 9.46.5: [...] ciuile ius, repositum in penetralibus pontificum, euolgavit fastosque circa forum in albo proposuit, ut quando lege agiposset sciretur [...]; Sérvio. Aen. 1.373: Tabulam dealbatam quotannis pontifex maximus habuit, in qua praescriptis consulum nominibus et aliorum magistratuum digna memoratu notare consueuerat domi militiaeque terra marique gesta per singulos dies, cuius diligentiae annuos commentarios in octoginta libros ueteres rettulerunt eosque a pontificibus maximis, a quibus fiebant, annales maximos appellarunt. Macróbio. Sat. 3.2.17: Pontificibus enim permissa est potestas memoriam rerum gestarum in tabulas conferendi et hos annales appellant equidem maximos quasi a pontificibus maximis factos. Aulo Gélio, NA 4.5.6: Ea historia de aruspicibus ac de uersu isto senario scripta est in Annalibus Maximis, libro undecimo, et in Verri Flacci libro primo Rerum Memoria Dignarum.
} 
com commentarii sacerdotais que chegaram até nós em inscrições, ${ }^{31}$ talvez esses textos incluíssem descrições de rituais religiosos realizados no ano, mas Cícero faz Catão lamentar que houvesse muita criatividade e inovações nos registros, como detalhes sobre a annona, e Sérvio diz que nomes de magistrados eram registrados, bem como eventos "domésticos e militares, na terra e no mar" (Aen. 1.373; Gell., NA, 2.28.4).

A modernidade acreditou que os Annales Maximi teriam como função precípua o registro de prodígios, hipótese que se apoia na atribuição da procuratio prodigiorum tradicionalmente vinculada ao colégio dos pontífices, mas as controvérsias são muitas. ${ }^{32}$ E Cícero parece afirmar que Múcio Cévola, pontifex maximus, decidiu encerrar os Annales maximi (De Or.. 2.52). Mas por quê?

Em 1971, Elizabeth Rawson levantou diversas questões sobre os Annales Maximi, relacionando-os às listas de prodígios e à escrita da história em Roma, bem como sobre o caráter "público" desses registros, argumentando que, possivelmente, os autores antigos que os citaram não leram os textos originais:

Tudo que podemos dizer com alguma segurança é que algo parecia impedir tanto analistas quanto antiquários de fazer uso dos Annales Maximi. Talvez fossem difíceis de consultar e de se ter acesso a eles - haveria mais de uma cópia? Cícero, de fato, não fala deles como tendo sido publicados. ${ }^{33}$

Rawson, para fundamentar sua afirmação, retoma Cícero. O orador, no $D e$ Diuinatione, afirma — na fala de Quinto Cícero — que a melhor referência para os prodígios são os textos dos historiadores, pois não existiriam registros oficiais. ${ }^{34}$ Bruce Frier, por sua vez, comenta a falta de evidência para a suposição de Theodor Mommsen de que a tabula recebera uma edição em 80 livros por Públio Múcio Cévola, pontifex maximus entre 130 e 115 a.C., argumentando que não há evidência de tal edição em textos do período republicano e, baseado na hipótese de que o principado augustano promoveu uma edição e revisão de antigos registros, como os Livros Sibilinos e os Fasti Capitolini, supõe que tal compilação dos Annales Maximi poderia datar desse momento. ${ }^{35}$ Frier também defende que os Annales Maximi existiriam desde o início da República,

\footnotetext{
${ }^{31}$ Os commentarii fratrum arualium e um commentarium dos Ludi Saeculares foram alguns dos raros documentos desse tipo que chegaram até nós; com base neles, especialistas modernos criaram suas hipóteses sobre outros possíveis commentarii sacerdotais.

${ }^{32}$ Cf. John Scheid, " Les annales des pontifes. Une hypothèse de plus. ", In: Convegno per Santo Mazzarino. Roma, L'Erma di Bretschneider, 1998, p. 199-220; John North, "The books of pontiffs", In: Claudia Moatti (Ed.), La mémoire perdue: recherches sur l'administration romaine. Coll. EFR-A, 243, Paris, École Française de Rome, 1998, p. 65-74; Susanne William Rasmussen, Public Portents in Republican Rome, Roma, L'Erma di Bretschneider, 2003, p. 35-52; Jörg Rüpke, Fasti sacerdotum: A Prosopographic of Pagan, Jewish, and Christian Religious Officials in the City of Rome, 300 BC to AD 499, Oxford, New York, Oxford University Press, 2005, esp. p. 36-38; Ana Rodriguez-Mayorgas, “Annales Maximi: Writing, Memory and Religious Performance in the Roman Republic", In: André P.M.H. Lardinois; Josine H. Blok; Marc G.M. van der Poel (Ed.), Sacred Worlds: Orality, Literacy and Religion, Mnemosyne Suppl., 8, Leiden, Brill, 2011, p. 235-253.

${ }^{33}$ Elizabeth Rawson, "Prodigy lists and the use of the Annales Maximi", Classical Quarterly, vol. 21, 1971, p. 158$69,168-9$.

34/dem, Ibidem, p. 166.

${ }^{35}$ Bruce Frier, Liber Annales Pontificium Maximorum: The Origins of the Annalist Tradition, Ann Arbor, University of Michigan Press, 1999, p. 193-200.
} 
com base em referências de historiadores, especialmente em Tito Lívio, A.u.c. I, 20. ${ }^{36}$ A meu ver, essa interpretação apresenta diversos pontos frágeis, especialmente o pressuposto de que os Annales Maximi e os Fasti Capitolini seriam "antigos registros", e não criações posteriores ao século III a.C., e o fato de não haver evidências seguras de que o governo augustano teria promovido tais revisões e edições. ${ }^{37}$ Ainda segundo a interpretação de Frier, os Annales Maximi já não eram mais publicados no século I a.C. e tinham perdido muito de sua credibilidade como fonte histórica. ${ }^{38}$

Seguindo Rawson e Frier, Robert Drews forneceu um longo comentário das referências antigas aos Annales Maximi. Para o autor, esses livros nunca foram compilados e publicados, existindo apenas nas tabulae pontificais e, na metade do século I a.C. já não mais existiam. Para ele, os Annales Maximi eram, basicamente, registros de prodígios para a procuratio, e seu desaparecimento está de algum modo relacionado com a diminuição do destaque dos prodígios nas ações do Senado e nas assembleias, o que considero discutível. Sua hipótese é a de que os Annales Maximi eram compilados pelos sucessivos pontifices maximi que, provavelmente, transferiam os registros temporários da tabula dealbata para rolos de papiro sem, contudo, apresentar evidências que fundamentem tal suposição ${ }^{39}$ e, no século I a.C., teriam se tornado obsoletos devido a uma "indiferença pública aos prodígios", detectável a partir de 63 a.C. Drews teve como base evidências (literárias e altamente discutíveis) de que, sob Augusto, um único prodígio teria sido aceito oficialmente, e, sob Tibério e Calígula, nenhum..$^{40}$ Para o autor, o abandono da prática de afixar os Annales Maximi na casa do pontifex maximus (a domus publica, situada no forum romanum) por Múcio Cévola "foi, talvez, a primeira tentativa da classe dominante de diminuir o interesse público pelos rituais expiatórios. A proibição do sacrifício humano em 97 a.C. foi uma tentativa mais segura, na mesma direção." ${ }^{11}$ Tais suposições, contudo, são anacrônicas e cristianizantes, sem respaldo numa análise rigorosa da documentação textual e material supérstite.

O problema dos Annales Maximi voltou à discussão na década de 1990, quando John Scheid publicou artigos sobre as características e as funções dos textos sacerdotais romanos, especialmente os Annales Maximi, que trouxeram

\footnotetext{
${ }^{36}$ Bruce Frier, Liber Annales Pontificium Maximorum: The Origins of the Annalist Tradition, Ann Arbor, University of Michigan Press, 1999, p. 107-119.

${ }^{37}$ Públio Múcio Cévola, um dos fundadores da jurisprudência romana e cônsul de 133 a.C. era, como Frier argumenta (Frier, op.cit, p. 179-200), um dos nobiles favoráveis a um maior envolvimento do populus nos negócios públicos (foi um dos nobiles que apoiaram as propostas de Tibério Graco), mas não há elementos que expliquem o suposto encerramento dos Annales Maximi. Segundo Frier, o famoso pragmatismo de Cévola talvez tenha sido o fator determinante, num momento em que o registro público era bastante eficaz, tornando os Annales Maximi obsoletos; Frier levanta a hipótese de uma edição augustana dos Annales Maximi, mas não há evidência para tal suposição.

${ }^{38}$ Bruce Frier, op. cit., p. 152. Ver contra: John Scheid, "Oral tradition and written tradition in the formation of sacred law in Rome", In: Clifford Ando; Jörg Rüpke (Eds.), Religion and Law in Classical and Christian Rome, Stuttgart, PawB 16, 2006, p. 16.

${ }^{39}$ Robert Drews, "Pontiffs, prodigies and the disappearance of the Annales Maximi", Classical Philology, vol. 83, n. 4, 1988, p. 289-299, 296.

40/dem, Ibidem, p. 297.

41/dem, Ibidem, p. 299.
} 
muitas questões sobre as competências pontificais relativas ao controle do tempo. ${ }^{42}$ Antes de tudo, Scheid, alterando o foco tradicional da discussão da escrita da história para a análise da religião e dos rituais, defendeu o caráter religioso desses textos e que os Annales Maximi resumiriam os acontecimentos importantes de cada ano, positivos e negativos para a urbs, extraídos dos commentarii pontificum. Os Annales Maximi, na interpretação de Scheid, registravam os acontecimentos relativos à pax ou à ira deorum, tendo como tema principal as relações da urbs com suas divindades. Para ele, o simples fato de os Annales Maximi serem afixados na domus publica, residência do pontifex maximus, indicava alguma publicidade desse registro.

As referências antigas insistem que a redação dessas tabulae era competência do pontifex maximus, mas podemos perguntar a quem se endereçavam tais informações. Para Scheid, o Senado e os magistrados deviam dispor de uma lista oficial dos acontecimentos do ano transcorrido e tinham de buscar informações relativas aos deuses nas atas públicas, no início de cada ano, para poder decidir sobre a pertinência do cumprimento, pelos novos cônsules, dos votos formulados no ano anterior, bem como sobre os prodígios. Chamando a atenção para o "silêncio das fontes" sobre o papel dos pontífices ${ }^{43}$ nessas sessões do Senado, Scheid comenta:

[...] parece difícil admitir que os cônsules e os senadores pudessem, sozinhos, estabelecer os dados necessários para decidir sobre o cumprimento dos votos ou sobre a expiação dos prodígios. De fato, havia dois debates nos quais tinham necessidade dos conselhos pontificais: no curso da provável relatio inaugural, constatando que os votos precedentes foram cumpridos e, depois, nas horas ou dias seguintes, quando dos debates sobre os prodígios subsidiários, que reclamavam uma procuração. Não poderíamos supor que a famosa Crônica do grande pontífice seria estabelecida tendo em vista tais decisões? O resultado do poder que, segundo as fontes, o grande pontífice tinha de receber os anúncios dos prodígios, das catástrofes e dos sucessos ao longo do ano, podia ter como objetivo estabelecer, no fim do ano, um tipo de relatório para os cônsules e o Senado. ${ }^{44}$

Segundo essa interpretação, o pontifex maximus, anualmente, fornecia ao Senado um relatório dos eventos públicos significativos. Sob tal base, emanada

\footnotetext{
${ }^{42}$ Os três principais artigos de John Scheid sobre o tema, na década de 1990, são: "Le temps de la cité et I'histoire des prêtes. Des origines religieuses de la histoire romaine," In: Marcel Detienne (Ed.), Transcrire les mythologies: Tradition, écriture, historicité, Paris, Albin Michel, 1994, p. 149-58; "Les archives de la pieté," In: Segolene Demougin (Ed.), La mémoire perdue: a la recherche des archives oubliées, publiques et privées, de la Rome Antique, Paris, Publications de la Sorbonne, 1994, p. 173-85; e "Les libres Sybillins et les archives des quindécemvirs," In: Claudia Moatti (Ed.), La mémoire perdue: recherches sur l'administration romaine, Coll. EFR-A, 243, Paris, École Française de Rome, 1998, p. 11-26.

${ }^{43}$ Ver Yann Berthelet, que recentemente defendeu de modo coerente a presença e a importância do colégio dos pontífices nos casos de procuratio prodigiorum, a partir da releitura das famosas "procurações anônimas" de Tito Lívio, em "Le rôle des pontifes dans l'expiation des prodiges à Rome, sous la République: le cas des 'procurations' anonymes", Cahiers Mondes Anciens. Anthropologie et Histoire des Mondes Antiques. $2011-2$. Disponível em: <http://mondesanciens.revues.org/index348.html>, acesso em: 3 de março de 2012.

${ }^{44}$ John Scheid, "Les annales des pontifes. Une hypothèse de plus," In: Convegno per Santo Mazzarino. Roma, L'Erma di Bretschneider, 1998, p. 199-220, 218.
} 
de uma grande autoridade religiosa, o Senado poderia tomar as medidas religiosas, de modo a fazer com que os cônsules cumprissem os votos formulados no ano anterior ou que uma procuratio prodigiorum fosse levada a cabo. A hipótese de leitura de Scheid tem como fundamento a ideia de que os pontífices agiam em virtude de seu ius, sem que fossem independentes de uma solicitação do Senado. Segundo Scheid:

A despeito daquilo que um mito moderno quis fazer crer, não havia livros religiosos ou sacerdotais contendo uma exposição completa da doutrina ou das liturgias. Os livros dos colégios sacerdotais eram relatórios e registros anuais de celebrações e decisões, na medida em que ocorriam. Eles se chamavam comentários. Esses documentos, às vezes antigos, eram uma mina de ouro para antiquários e historiadores, que deles extraíam numerosas informações para comporem seus tratados, aos quais seus contemporâneos deram o nome de libri sacerdotum, pontificum etc., contribuindo, assim, para criar um mito que teve uma longa vida. ${ }^{45}$

Mais recentemente, Ana Rodriguez-Mayorgas, ${ }^{46}$ numa análise rigorosa da documentação supérstite, partiu da premissa tradicional de que os Annales Maximi existiam e de que sua origem se deu na República arcaica e discutiu algumas questões sobre sua conservação, transmissão e publicização, com base nas afirmações de autores antigos de que o pontifex maximus mantinha a tabula disponível para o público. A autora questionou o quão "públicas" seriam essas informações. Comparando a importância do suposto caráter público desses registros com as XII Tábuas e com os Fasti de Cneu Flávio, de 304 a.C., pergunta por seu conteúdo. Seguindo as teses de Frier, aceita as declarações de Cícero e de Sérvio de que os Annales Maximi eram registros de eventos importantes ocorridos no ano, particularmente prodígios, sendo uma espécie de sumário de eventos, informações gerais, não problemáticas nem restritas, e conclui ser difícil imaginar os Annales Maximi como uma fonte privilegiada de informações, ressaltando, contudo, sua importância na constituição da memória religiosa da urbs.

Segundo as linhas gerais deste debate, os Annales Maximi seriam apenas um dos componentes do registro pontifical, e não o mais importante para o estudo da religião romana, pois registrava aparentemente o que também era registrado por outros suportes. Para Federico Santangelo, mais importantes para a análise da religião romana seriam os commentarii pontificum, que não visavam à publicação. ${ }^{47}$ Mas a questão sobre o quão secretos eram os commentarii pontificum é muito difícil de tratar; as evidências são poucas, e os problemas, muitos. Numa passagem do De domo sua, 138, Cícero se refere a

\footnotetext{
45John Scheid, An Introduction to Roman Religion, Bloomington, Indianapolis, Indiana University Press, 2003, p. 111 ${ }^{46}$ Ana Rodriguez-Mayorgas, "Annales Maximi: Writing, Memory and Religious Performance in the Roman Republic," In: André P.M.H. Lardinois; Josine H. Blok; Marc G.M. van der Poel (Ed.), Sacred Worlds: Orality, Literacy and Religion, Mnemosyne Suppl., 8, Leiden, Brill, 2011, p. 235-253.

${ }^{47} F e d e r i c o$ Santangelo, "Pax deorum and Pontiffs," In: James H. Richardson; Federico Santangelo, Priests and State in the Roman World, Stuttgart, Franz Steiner Verlag, 2011, p. 161-186. Cf. também Jersky Linderski, "The Augural Law," ANRW 2.16.3, 1986, p. 2146-2312.
} 
casos nos quais os pontífices foram consultados sobre procedimentos adequados a uma dedicação, por exemplo, quando o censor Caio Cássio consultou o colégio sobre a dedicação de uma estátua da Concordia e a consulta do pretor Sexto Júlio sobre a proposta de dedicação de um altar pela vestal Licínia. Cícero especifica que esses exemplos não foram extraídos dos registros pontificais, e sim de senatus consulta e de arquivos de magistrados, que incluíam respostas de pontífices a consultas como essas - Cícero discursava, então, para o colégio dos pontífices e diz saber que os commentarii pontificais mantinham os registros desses episódios e que garantiam aos sacerdotes um guia claro para suas decisões (De domo sua, 136). Isso talvez seja um indício de que os commentarii não eram públicos, nem acessíveis, mesmo para membros de outros colégios sacerdotais de destaque na res publica, como o áugure Cícero, pelo menos naquele momento, quando citações diretas dos commentarii pareciam ser evitadas. ${ }^{48}$

Sem atentar para as variantes interpretativas, depreende-se que a discussão sobre as fontes documentais romanas concentrou-se nos registros sacerdotais, especialmente nos Annales Maximi. A atenção tem sido dada à organização e ao conteúdo desses documentos, além da discussão sobre a relação entre os Annales Maximi, as tabulae pontificum e os commentarii e, neste ponto, a contribuição de Jörg Rüpke ao debate merece destaque por seu rigor e por lançar mão de tipos documentais distintos, ao propor sua interpretação do tema dos Annales Maximi.

Em Fasti sacerdotum, Rüpke chama a atenção para a dificuldade em relação às fontes de informação sobre os sacerdócios romanos e, no que tange aos commentarii pontificum, ressalta que:

Duas circunstâncias importantes estão relacionadas a 249 a.C., um ano que talvez marque o início da prática do registro de prodígios nos commentarii. A primeira concerne aos Jogos Seculares daquele ano. Muito pouco se sabe sobre concepções mais antigas do saeculum, mas é certo que aqui, com a promessa de repetir um evento após cem anos, foi introduzida na prática cultual um período fixo que, como transcendia qualquer período concebível de vida humana, necessitava de um cuidadoso registro cronológico e de certo grau de institucionalização. Não se trata de dizer que esta era a única função que cabia aos commentarii, mas os Jogos Seculares representam um contexto que torna concebível o início desses registros. [...] A segunda circunstancia é relacionada com o pontifex maximus do ano 249 a.C., a primeira pessoa a quem a iniciativa de tais registros pode ser atribuída. Desde cerca de 250, Tibério Coruncânio, originário de Túsculo,

\footnotetext{
48Sobre esses dados e seu detalhamento, ver Ana Rodriguez-Mayorgas, "Annales Maximi: Writing, Memory and Religious Performance in the Roman Republic", In: André P.M.H. Lardinois; Josine H. Blok; Mark G.M. van der Poel (Ed.), Sacred Worlds: Orality, Literacy and Religion, Mnemosyne Suppl., 8, Leiden, Brill, 2011, p. 235253, e Elizabeth Rawson, "Prodigy lists and the use of the Annales Maximi", Classical Quarterly, vol. 21, 1971, p. 158-69, 168-9.
} 
foi o primeiro plebeu a ocupar tal posto sagrado; ${ }^{49}$ ele possivelmente foi o primeiro a ser eleito nos comitia tributa modificados [...] Pompônio ${ }^{50}$ diz que ele foi o primeiro que ofereceu aconselhamento legal público. ${ }^{51}$

Para Rüpke, portanto, os commentarii pontificum provavelmente foram criados a partir de 249 a.C., pelo primeiro plebeu a ser pontifex maximus, Tibério Coruncânio, argumentando que o processo pelo qual a atividade literária se desenvolveu foi lento e gradual, excluindo uma "edição" extensiva do material textual existente. $\mathrm{O}$ autor sugere que 249 a.C. seja o início do processo de registro dos eventos religiosos na forma escrita, com Coruncânio instituindo o registro de commentarii pontificais contínuos, cuja finalidade não era escrever história, mas manter um registro escrito dos eventos com o propósito de coletar e documentar dados e precedentes para questões relativas à lei e ao ritual:

O quadro que apresentamos dos commentarii de Coruncânio sugere dois corolários: enquanto o início dos registros regulares pode ser relacionado com o início de novas atividades mencionadas, podemos assumir que a acumulação de fatos também era de certo modo orientada ao passado. [...] Se Lívio ou Valério Antias tinham dados que chegavam a 332 a.C., este período de oitenta anos do marco de 249 a.C. corresponde ao horizonte de três gerações normalmente acessível à história oral. ${ }^{52}$

Para Rüpke, as tabulae pontificum e os commentarii pontificum seriam inter-relacionados:

Se esta caracterização é correta, o material citado [pelos autores antigos] dos commentarii ou libri pontificum pelos antiquários deve ser visto como pertencente aos commentarii iniciados por Coruncânio. [...] Todas as fontes relativas à atividade "historiográfica" dos pontífices relatam que a cada ano o pontifex maximus publicava uma tabula dealbata listando os eventos mais importantes. De acordo com nossa reconstrução do caráter dos commentarii pontificum, essa tabula pode não ter sido um registro primário, e sim extratos direcionados a um público mais vasto. ${ }^{53}$

Em relação ao conteúdo das tabulae, a menção do fragmento de Catão a eclipses e preços de grãos sugere outra interpretação: no contexto do século III a.C., ambos eram eventos calculados ou previstos por especialistas religiosos, e tais anúncios podiam evitar problemas, garantindo a ordem social. ${ }^{54}$ Rüpke

\footnotetext{
${ }^{49} \mathrm{~A}$ lex Olgunia, datável de 300 a.C., abriu a possibilidade de plebeus ocuparem sacerdócios nos colégios dos pontífices e dos áugures.

50Sobre a referência a Pompônio ver Dig. 1.2.2.35.

51Jörg Rüpke, Fasti sacerdotum: A Prosopographic of Pagan, Jewish, and Christian Religious Officials in the City of Rome, 300 BC to AD 499, Oxford, New York, Oxford University Press, 2005, p. 31-2.

52/dem, Ibidem, p. 33.

53/dem, Ibidem, p. 33

${ }^{54 J o ̈ r g ~ R u ̈ p k e ~ a p r e s e n t a, ~ c o m o ~ b a s e ~ p a r a ~ t a l ~ i n t e r p r e t a c ̧ a ̃ o, ~ e s p e c i a l m e n t e ~ P l u t a r c o, ~ A e m . ~ 17, ~ s o b r e ~ o s ~}$ procedimentos rituais preparatórios para o eclipse anunciado antes da batalha de Pydna, em 168 a.C., e Tito Lívio, 44.37.6, em seu comentário sobre a intenção da ação: ne quis id pro portento acciperes.
} 
também aponta dificuldades nas interpretações que indicam os prodígios como a principal finalidade dos Annales Maximi: o registro de prodígios era apanágio das magistraturas, designadamente dos cônsules e dos pretores urbanos, e apenas os prodígios reconhecidos por tais magistrados como de interesse público eram encaminhados aos colégios sacerdotais para seu tratamento. ${ }^{55}$

A religião romana é muito menos rígida e
menos esquemática do que pretendem os
historiadores modernos, e o jogo entre inovação e
conservadorismo atingia também os especialistas
"intelectuais" da religião e da lei

Se os commentarii pontificum começaram com Coruncânio, a publicação da tabula persistiu até Múcio Cévola, segundo Cícero, e a publicação da compilação dos Annales Maximi em oitenta volumes vem sendo associada a essa ruptura. Mas, se Múcio Cévola encerrou a redação da tabula, teria encerrado os commentarii? Provavelmente, não. No século I a.C., textos concernentes às regras dos rituais constituíam um gênero textual importante e, a crermos em Macróbio (Sat.3.13.10-2), os commentarii do pontifex maximus continuaram a ser redigidos e mantidos. Para Rüpke, a ideia de Mommsen de que os Annales Maximi foram compilados e publicados por Múcio Cévola merece, portanto, reconsideração. ${ }^{56}$ A questão de como Cévola teria compilado em oitenta volumes registros pontificais de, pelo menos, meio milênio de existência foi um dos maiores elementos das críticas à interpretação de Mommsen. Tal problema é menor se, segundo Rüpke, lidamos com a hipótese de que os registros foram iniciados em 249 a.C., cobrindo, portanto, um período de tempo de menos de 200 anos. Se considerarmos que tabulae antigas foram preservadas - apesar de Rüpke considerar quase absurda a ideia de que tais tabulae fossem armazenadas na casa do pontifex maximus -, haveria menos de 200 tabulae a compilar, sem excluir a possibilidade do registro de acontecimentos marcantes anteriores ao século III a.C. Rüpke argumenta que Cévola, à época dessa presumida compilação, encontrava-se numa posição política ainda frágil, após a morte de Tibério Graco, cujas reformas apoiara, o que também poderia explicar suas documentadas compilações do sistema jurídico romano pelas quais se tornou uma referência inquestionável para a elite governamental romana.

\footnotetext{
55Jörg Rüpke, Fasti sacerdotum: A Prosopographic of Pagan, Jewish, and Christian Religious Officials in the City of Rome, 300 BC to AD 499, Oxford, New York, Oxford University Press, 2005, p. 34. Ver também S. Rasmussen, Public Portents in Republican Rome, Roma, L'Erma di Bretschneider, 2003, p. 35-52;, para os procedimentos da procuratio prodigiorum.

${ }^{56}$ Jörg Rüpke, op cit. p. 35, contra Bruce Frier, Liber Annales Pontificium Maximorum: The Origins of the Annalist Tradition, Ann Arbor, University of Michigan Press, 1999, p. 193-200.
} 
Em suma, para Rüpke, os commentarii existiam para uso interno do colégio pontifical, assim como os commentarii de outros collegia, e eram mantidos pelo pontifex maximus, representando um conjunto documental de grande autoridade, passível de ser utilizado na construção do passado. Cévola teria reconhecido o potencial político dos commentarii pontificum e de seu resumo, a tabula dealbata, citada por autores antigos, e os teria utilizado na criação de uma literatura "apócrifa", os Annales Maximi. A novidade da publicação dos Annales Maximi teria sido obscurecida pela referência às tabulae pontificum, e os livros em questão foram considerados não como uma inovação, e sim como uma "nova edição" do material antigo, garantindo sua autoridade religiosa e, consequentemente, política. Assim, para Rüpke, os commentarii do colégio dos pontífices foram iniciados em 249 a.C. e anualmente era feito um extrato inscrito numa tabula colocada do lado externo da casa do pontifex maximus. Já os Annales Maximi representam uma edição publicada dos commentarii, produzida por Múcio Cévola na República tardia.

À guisa de conclusão, considero que a interpretação rigorosa e bem documentada de Rüpke sobre os Annales Maximi resolve uma série de dificuldades e dá um novo significado a esses "livros" que tanto destaque tiveram (e têm) na análise historiográfica moderna. Seja como for (e a polêmica em relação a este tema ainda é grande, e as questões são mais abundantes do que as conclusões), o mais importante, a meu ver, é perceber que a tradição religiosa na Roma médio e tardo-republicana era apenas parcialmente transmitida em textos escritos e mantida em arquivos privados, como os dos collegia sacerdotais, e não compilada e sistematizada num corpus qualquer. John Scheid ${ }^{57}$ observou que as tentativas modernas de reconstrução da literatura religiosa romana falharam - e costumam falhar - por dois motivos principais: por sua incompreensão da natureza do ritualismo romano e por não considerar a forma e as intenções dos textos dos colégios sacerdotais. Para Scheid, a tradição religiosa romana consistia em dois aspectos principais: a) no calendário ritual e em instruções precisas para os oficiantes (libelli e formulae), e b) na jurisprudência religiosa. As respostas dos sacerdotes às consultas feitas a eles eram registradas não apenas nos seus relatórios anuais (commentarii), mas também nos relatórios senatoriais, especialmente quando se tornavam senatus consulta ou editos.

Desse modo, os arquivos sacerdotais parecem ter sido acessíveis apenas aos sacerdotes, e quem quisesse - e pudesse - consultar a jurisprudência pontifical, por exemplo, tinha de fazer uma longa pesquisa nos arquivos senatoriais, pois nada disso teria sido fixado em livros específicos. Colégios sacerdotais distintos mantinham seus commentarii com seus registros anuais, mas esses não podem ser considerados, rigorosamente falando, "livros sagrados".

\footnotetext{
${ }^{57}$ John Scheid defende o caráter oral da tradição religiosa romana e o caráter ritualístico da religião romana, que fundamenta seu caráter oral. Scheid comenta as dificuldades modernas em relação ao ritual, por exemplo, na oposição espiritualidade interior versus prática exterior, e em relação aos sacerdócios, por exemplo, na crença de que haveria uma religiosidade inata confiscada pelos sacerdotes e reduzida ao sistema ritual e que o veículo, ou instrumento dos sacerdotes, são seus livros, cf. esp.: John Scheid, "Oral tradition and written tradition in the formation of sacred law in Rome," In: Clifford Ando; Jörg Rüpke (Ed.), Religion and Law in Classical and Christian Rome, Stuttgart, PawB 16, 2006, p. 16-19.
} 
Enfim, vemos quão incipiente é o conhecimento atual sobre tais questões, bem como que os textos antigos não apresentam um corpo definitivo e cabal de conceitos e definições nos quais possamos nos apoiar. Como Scheid bem argumentou, ${ }^{58}$ a religião romana é muito menos rígida e menos esquemática do que pretendem os historiadores modernos, e o jogo entre inovação e conservadorismo atingia também os especialistas "intelectuais" da religião e da lei.

A religião é um importante elemento no âmbito da comunicação pública e, no caso de Roma, seu estudo permite-nos observar alguns momentos do processo de consolidação do espaço público, sendo que os textos dos colégios sacerdotais inseriam-se e alimentavam a vida pública romana. Os commentarii pontificum inseriam-se nesse movimento de organização e compilação de regras ocorrido a partir do século III a.C., radicado no incremento da escrita e na sistematização das práticas e das instituições em leis, calendários e normas, num processo que Rüpke definiu como "racionalização instrumental" da linguagem do ritual, visando à posse e ao uso desses elementos, ${ }^{59}$ e que Mary Beard destacou, ao lidar com as relações entre religião e escrita, observando-as a partir dos temas da "codificação religiosa" e da "competição política" e discutindo as implicações da escrita em Roma e seu impacto nos sistemas religiosos para a vida política e a ordem social. ${ }^{60}$ Os commentarii, não apenas de colégios sacerdotais, mas também dos magistrados, são exemplos da escrita como instrumento de comunicação e controle social. Os Annales Maximi, compilados e publicados por Cévola, se aceitarmos a hipótese de Rüpke, se constituem como um exemplo da união entre escrita e religião como forma de competição política. Esses textos eram importantes meios de comunicação pública para os nobiles romanos entre si, entre estes e as elites municipais, entre nobiles e os demais grupos que formavam o populus na urbs e no Imperium.

\footnotetext{
58 John Scheid, "Oral tradition and written tradition in the formation of sacred law in Rome," In: Clifford Ando; Jörg Rüpke (Ed.), Religion and Law in Classical and Christian Rome, Stuttgart, PawB 16, 2006, p. 33.

${ }^{59}$ Jörg Rüpke, Religion in Republican Rome: Rationalization and Ritual Change, Philadelphia, University of Pennsylvania Press, 2012.

${ }^{60}$ Mary Beard, "Documenting Roman Religion," In: Claudia Moatti (Ed.), La mémoire perdue: recherches sur l'administration romaine. Coll. EFR-A, 243, Paris, École Française de Rome, 1998, p. 75-101; "Ancient literacy and the function of the written word in Roman religion," In: Mary Beard et al, Literacy in the Roman World, Journal of Roman Archaeology, Suppl. 3, 1991, p. 35-54; "Writing and Religion," In: Sarah I. Johnston, Ancient Religions, Cambridge-Mass, Harvard University Press, 2007, p. 127-138.
} 